\title{
Financial Management in Religious Non-Profit Organizations: A Mission Based Approach to Ratio Analysis
}

\author{
Ruhaya Atan ${ }^{1}$, Saunah Zainon ${ }^{1}$, Sharifah Aliman ${ }^{2}$, Roland Yeow Theng Nam ${ }^{3}$ \\ ${ }^{1}$ Faculty of Accountancy, Universiti Teknologi MARA, 40450 Shah Alam, Selangor, Malaysia \\ ${ }^{2}$ Faculty of Computer and Mathematical Science, Universiti Teknologi MARA, 40450 Shah Alam, Selangor, Malaysia \\ ${ }^{3}$ Boy's Town, Singapore \\ www.ros.gov.my, ruhaya@salam.uitm.edu.my
}

\begin{abstract}
Religious non-profit organizations (RNPOs) exist to provide a variety of programs and services. They have an important niche in a wide range of social, human, education, health, and community services to their stakeholders. The reason for RNPOs' existence is its mission and thus, mission becomes the central thrust for RNPOs' existence and operations. Therefore, it is appropriate to focus on the financial management of RNPOs in their association with mission based approach to ratio analysis. A mission based approach to ratio analysis for RNPOs is one of the ways for a long way of having the financial performance measures for RNPOs. Such analysis through the use of ratios helps identifies the financial performance of RNPOs in actual faith of mission. The measures of financial performance concerning performance efficiency ratio (PER) and operating expense ratio (OER) were constructed in this study. The ratios were generated for 60 RNPOs and were considered a good measure of the efficiency in which the organization fulfilled its mission.

Index Terms - financial performance, measurement, ratio analysis, religious non-profit organization.
\end{abstract}

\section{Introduction}

Malaysia has a population of 23.27 million consisting of 61 percent Malays, 30 percent Chinese, 8 percent Indians and 1 percent of other ethnic groups. Malaysia is unique because of its community diversity of races, religions and cultures. Islam is the state religion and most dominant in Malaysia. About 58 percent of the total population of Malaysia practices Islam. In spite of a predominant Islamic population, the status of religious freedom or freedom to practise any religion has been guaranteed by the constitution of the country. This has affected the society at large, reflecting the establishment of non-profit organizations (NPOs) in this country. There are 6,782 religious non-profit organizations (RNPOs) registered with the Registry of Society (ROS) as at April 2011. This constitutes the third largest group among all other categories of registered NPOs in Malaysia. RNPOs provide a variety of services to societies. With their existence, they have an important niche in a wide range of services, be it social, education, health and community to their stakeholders. They often meet needs that would not be met by other organizations

Their activities continue to operate indefinitely as programs of the religious organizations, although they are not eligible for tax exempt status under the Section 44(6) of the Income Tax Act. The reason for RNPOs' existence is its mission which is a central thrust for RNPOs' existence and operations1. It is therefore appropriate to focus on the financial performance of RNPOs in their association with the mission as well as, the stakeholders who are served by that mission. Yet, little is known about their management, operations and in particular, its financial performance related to their mission. Furthermore, there is a difficulty to assess and evaluate the performance because the lack of performance measures magnitude. A general lack of performance measures magnitude has contributed to NPOs' array of financial measures2. This lack of performance measures magnitude for RNPOs poses problems for both researchers and practitioners to develop normative conclusions3. Despite the lack of performance measures magnitude for RNPOs, it is noticed that evaluation of financial performance by ratio analysis helps identify an organizations' performance by detecting financial anomalies and focusing attention to the organizational issues4. Ratio analysis also provides opportunities for past performance evaluation for an organization to map its future direction. This study focuses on mission as the central thrust in the use of ratio analysis and develop financial performance model that can be applied to RNPOs.

\section{Review of Literature}

Financial performance measures or objective measures are an essential component in assessing overall organizational effectiveness ${ }^{5}$. However, there is not an easy way to measure performance of NPOs due to the absence of profit motive, difficulties in measuring outputs, lack of similar objectives and lack of consensus in evaluating performance. These have resulted in a serious gap in the financial performance measures. The purpose of RNPOs is not to maximize income, but to carry out the mission of the organization, which usually focuses on the provision of services. In addition, organizational performance is complicated by the absence of single end product and the presence of multiple stakeholders group ${ }^{6}$.

Despite the gap, there are many tested financial performance measures in the NPOs literature ${ }^{3}$. Financial performance measures or financial health of RNPOs is important in making resource allocations decisions and further understanding of this financial health is crucial in achieving the long-term success and survival of these organizations? For RNPOs, these financial measures or indicators are signals used to convey evidence that assessment of the desired missions are being achieved. Financial performance measures have also been recognized as essential components of RNPOs as they are accountable to the use of donors' money in pursuing social missions ${ }^{8}$. 
There were numerous discussions with regards to specific financial performance measures for RNPOs because the variety of the performance measures used. High level financial performance indicators were interpreted to be ratios. Financial indicators (ratio analysis) were also commonly used as one form of financial performance measurement used in assessing the organizational strengths and weaknesses in NPOs studies. Using data gathered from university foundations for the period 1990 to 1999 , evaluation of financial performance ratios -fundraising efficiency, public support and fiscal performance by using factor analysis ${ }^{3}$. The study provided a viable model of performance ratios that can be used by the researchers and practitioners of NPOs using ratios measuring the availability and use of financial resources to support the organizational mission were conducted ${ }^{9}$. They used five ratios for financial resources availability in five types of NPOs: Arts, Culture and Humanities, Education, Human Needs, Community Services and Health. On the other hand $^{10}$, used ratio analysis to answer a different set of questions: (i) Are the goals of the organization consistent with the financial resources it needs to finance those goals? (ii) Is the organization maintaining inter generational equity? (iii) Is there an appropriate matching between the sources from which resources are derived, and the uses to which they are put and (iv) Are present resources sustainable? The series of these questions imply the underlying goals or missions for the organization. The effect of financial ratios, particularly the efficiency ratios on donations (as a measure of financial performance) has been studied by several authors. Ratio analysis is a well established tool to evaluate an organization's profitability, liquidity and financial stability ${ }^{4}$. Financial ratio analysis also formalizes and quantifies financial data to facilitate comparison within an organization. Every ratio is designed to discover certain types of warning signs in relation to the underlying state of health of the organization. The warning signs may suggest a proper treatment plan to rectify the current situation. The roles of five of the most commonly used ratios are summarized in Table 1.

Table.1. Role of Ratios in NPOs Performance Evaluation

\begin{tabular}{|l|l|}
\hline Ratios & Role of Ratios in NPOs Performance Evaluation \\
\hline Asset turnover & $\begin{array}{l}\text { Matches assets and goals. Slow turnover assets } \\
\text { required considerable investment and reduce } \\
\text { flexibility. }\end{array}$ \\
\hline $\begin{array}{l}\text { Profitability } \\
\text { and return on } \\
\text { invested } \\
\text { capital }\end{array}$ & $\begin{array}{l}\text { Analyses intergenerational equity and the match } \\
\text { between source and uses of money. Neither excessive } \\
\text { profits nor losses are desirable. }\end{array}$ \\
\hline $\begin{array}{l}\text { Liquidity and } \\
\text { solvency }\end{array}$ & $\begin{array}{l}\text { Matches sources and uses of financial resources. Is the } \\
\text { organization flirting with insolvency in the short-term } \\
\text { or in the long-term? }\end{array}$ \\
\hline $\begin{array}{l}\text { Percentage of } \\
\text { revenues, by } \\
\text { source }\end{array}$ & $\begin{array}{l}\text { Analyses quality of revenues and relation to mission. } \\
\text { Is the organization excessively dependent on a few } \\
\text { revenue sources? Are revenue sources consistent with } \\
\text { organization's mission? }\end{array}$ \\
\hline $\begin{array}{l}\text { Percentage of } \\
\text { expenses, by } \\
\text { type }\end{array}$ & $\begin{array}{l}\text { Analyses quality of expenses and relation to mission. A } \\
\text { large percentage of fixed expenses decrease the } \\
\text { organization's flexibility. Are expenses consistent with } \\
\text { the organization's mission? }\end{array}$ \\
\hline
\end{tabular}

Source: Abraham, A., Journal of American Academy of Business, 10,1 (2006).
There are primary ratios that are often used as indication to support whether the organizations are fulfilling its mission. Financial measures such as level of income derived from clients compared to expenses and asset ratio have been suggested as the financial ratios to measures efficiency.

\section{Financial Performance Model in RNPOs}

In order to measure financial performance in RNPOs, it is essential to consider the organization's mission that has been discussed earlier in the previous section. The questions posed can be answered through the capability of ratio analysis. The capability of ratio analysis in assessing an organization's current financial state is indubitable since these ratios are capable in assessing the liquidity position and mission's fulfilment. In support of their activities, the organization needs the finances and resources for the organization to continue its operations. At the same time, ratio analysis addresses the ways in which resources are used to fulfil the organization's mission. Consequently, this study presents the efficiency ratios that give indications of how the financial resources available and are used to support its mission. Efficiency ratios measure the extent to which expenses are related to mission divided by total expenses. The financial performance measures used in this study were based on performance efficiency ratio (PER) and operating efficiency ratio (OER). The purpose of the performance efficiency ratio is to ensure whether the expenses spent are consistent with the organization's mission. The ratio was computed by dividing total revenues to total expenses.

\section{Method}

This study was based on the financial statements for the financial year of 2010 for 81 RNPOs, which are partly the 13 categories of national NPOs. Out of 81 annual returns analyzed, only 60 annual returns have complete data from which the PER and OER were computed. Sub groupings of the sample data by state were Kuala Lumpur and Selangor (16), Kelantan and Terengganu (12), Sarawak (7) and Sabah (25). The measures of financial performance using these two ratios were constructed in this study. The ratios were generated for each RNPO and all these ratios are a good measure of the efficiency with which the organization was fulfilling its mission.

\section{Results and Discussion}

\subsection{Descriptive Analysis}

This study divided the sample according to the presence of religious practices in Malaysia from Islam, Buddhism, Hinduism, Christian and others (Sihkism, Daoism and Confucianism). The largest portion of RNPOs was from Buddhism (41; 68.3\%), followed by Christian (10; 16.7\%), Islam $(6 ; 10 \%)$ and Hinduism $(3 ; 5 \%)$. This profile of predominantly Buddhist RNPOs, were led by majority the founders and volunteers whose actions are driven by passionate beliefs in their mission. 
According to categories provided by the ROS, RNPOs range in size from the large RNPOs with total current assets of RM4 million or more, to the medium-size RNPOs with total current assets ranging from RM400,000 to RM1 million and to the small RNPOs with total current assets of RM100,000 or less. All of these have a board of trustees, and the organizations are independent entities. The board size in the sample averaged 14 members, with $13(21.7 \%)$ RNPOs have below 10 members and only one RNPO containing more than 30 members. It is also noted that only $11(18.3 \%)$ financial statements prepared by RNPOs in this present study were audited by the external auditors and none audited by the Big Four auditors. In contrast, about half of the organizations in the sample established the position of internal auditors in their organizations.

\subsection{Financial Performance by Ratio Analysis}

\subsubsection{Performance Efficiency Ratio}

The analysis of expenditure in this study is extracted from the financial statements of RNPOs. There are two major sources for the expenses: (i) Statement of Income and Expenditure and (ii) Statement of Receipts of Payments. To facilitate the analysis, the figures for expenses are derived from the Statement of Receipts and Payments. Through content analysis performed in this study, it was found that the expenses reported by RNPOs in the Statement of Receipts and Payments were not classified by its functions, but mostly reported in general in the list of all expenses incurred during the financial year. Therefore, the expenditure needs to be first classified into the programme expenses and the administrative expenses. Analysis of financial statements also revealed that no standardisation of format in the preparation of the financial statements. As a result, there is a difficulty in searching the Statement of Receipts and Payments which appeared at different locations in variety of formats. The purpose of this study was to evaluate the financial performance efficiency of RNPOs using a mission based approach to ratio analysis. Figure 1 reported the level of PER accordingly.

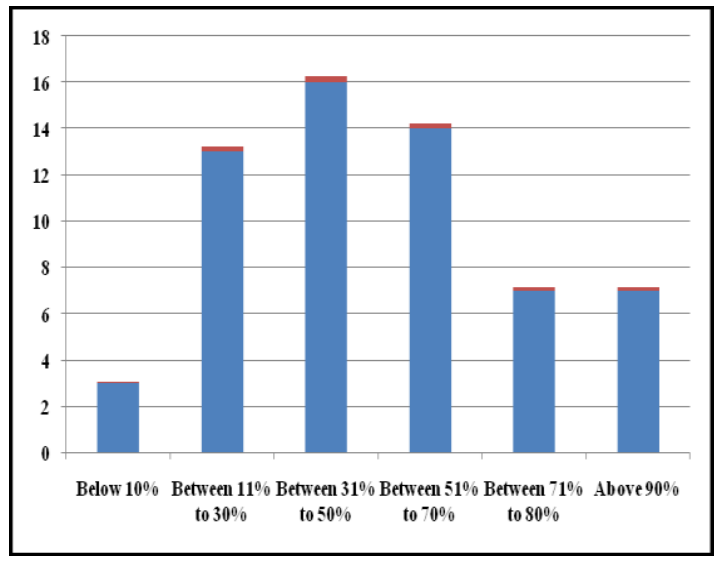

Fig. 1. Level of Performance Efficiency Ratio
Figure 1 reported that only $23.3 \%$ of RNPOs spent program expenditure above $70 \%$ and there were seven $(10 \%)$ RNPOs spent above $90 \%$ for program expenditure. This indicated that the organizations have been operated efficiently according to its mission. The majority $(26.7 \%)$ of the organizations have had a balanced between their amount spent on program expenditure and administrative expenditure. They spent between $31 \%$ to $50 \%$ of its expenditure for program and administrative expenditure. Nevertheless, there were four (6.6\%) RNPOs spent below than $10 \%$ for the program expenditure. Those RNPOs spending less than $10 \%$ of their budget on program expenses are not living up to their missions. As the results showed, a great variation existed from the lowest PER of $4 \%$ to the maximum of $100 \%$ PER.

This result is anticipated because the majority of RNPOs have no policies in financial management. They operate in unregulated environment and they do not engage in advocacy, especially with respect to the financial management. They are concerned about the organization itself and its programs rather than the financial management. Thus, there existed a range of PER from as low as below $10 \%$ to as high as above $90 \%$. Furthermore, RNPOs are not eligible for the tax exempt status from the Inland Revenue Department (IRD). Thus, they are not under such an obligation to apply for the tax exempt status. The IRD establishes two conditions for all NPOs (except for religious and political NPOs) for tax exempt status : (1) it must be established in Malaysia for charitable purposes only and (2) the organization must spend at least $50 \%$ (or such percentage as may be determined by the Director General) for its income including donation received in the previous year for program activities which were approved to achieve its objectives and missions [para 3.4 Section 44(6)].

\subsubsection{Operating Expense Ratio}

In an effort to determine the ability of RNPOs to control their expenses, performance measure ratios of total revenues to total expenses were computed. This ratio measures the total expenses associated with managing and operating the RNPOs. These consist primarily of operational expenses such as salary, wages, insurance, and supplies depending upon the mission of the organizations. The ratio of operating expenses is computed in generating the revenues for the organization. The OER is important because it is an indicator of how efficient the organization is being managed from the resources that they secured. This ratio is recommended to make an initial assessment of an organization's financial health. It is financial viability of an organization to continue to achieve its operating objectives and fulfill its missions over the long-term. If the ratio is greater, then the existing expenses could be repaid from the resources available. The larger the ratio means the higher amount of revenues that the organization generated. In other words, a ratio of 1 or greater indicates that, as of the balance sheet date, an organization is clearly financially healthy because it has sufficient revenues to satisfy debt and expenses obligations. For those ratios below 1 however, there 
is no absolute threshold for which organizations are to be no longer financially viable. Eventually, a weak financial condition will impair the ability of an organization to fulfill its mission. Table 2 reported the level of OER for RNPOs.

The results indicate two RNPOs in the sample obtained the OER above 4. Majority (61.7\%) RNPOs OER is in the range of 1 to 2 .

Table 2: Level of Operating Efficiency Ratio (OER) for RNPOs

\begin{tabular}{|l|l|l|}
\hline Range of OER & Number of RNPOs & Percentage (\%) \\
\hline Below 1 & 14 & 23.3 \\
\hline Range between 1 to 2 & 37 & 61.7 \\
\hline Range between 2 to 4 & 7 & 11.7 \\
\hline Above 4 & 2 & 3.3 \\
\hline Total & 60 & 100 \\
\hline
\end{tabular}

These results indicate that most RNPOs have sufficient revenues to operate in healthy financial environment. The ratio of total revenues to total expenses in a study of YMCAs as an indicator of fiscal performance was also used ${ }^{11}$. Their measures for ratios had factor loadings exceeding .97, with an eigenvalue of 1.8 and explaining 30 percent of the variance among the performance categories. This is consistent with findings, data shows that about at least two third of RNPOs spent their budget on the programs and services they exist to provide $^{11}$.

\section{Conclusions}

In RNPOs, the sense of "doing God's work" with the sense of trust often tender RNPOs to put less emphasis on sound financial management. In addition, many founders and management of RNPOs are unfamiliar with practices of professional non-profit management. Specifically, this study found that financial performance measures in the form of ratios are affiliated with the organizations' missions. These performance measures by the use of two ratios - PER and OER can be seen as distinctive dimensions of measurement in judging the financial health of RNPOs. The results from this study provide the stakeholders with a parsimonious number of financial performance measures. This enables relatively easy assessment of RNPOs financial performance.

Succinctly, financial ratios, by itself should guide management decision making. However, there is much about RNPOs that cannot be quantified through ratio analysis, for example, leadership, reputation or community support ${ }^{12}$. In addition, different RNPOs have different needs for financial analysis and tend to emphasize different ratios. The educational sector carefully monitors their resource inflows and outflows based on per capita or per student. Health sector examines the structures of operating revenues, especially concern over patient services or type of expenses by condition or treatment. Financial management must be seen as important in the religious context. RNPOs founders, managers, leaders and volunteers lack in the required skills, competent, qualifications and experience in financial management.

\section{Acknowledgments}

This study was supported by the grants from the Accounting Research Institute (ARI), Faculty of Accountancy, Universiti Teknologi MARA, Shah Alam, Malaysia.

\section{References}

[1] Abraham, A., Journal of American Academy of Business, 10,1 (2006).

[2] Herman, R.D. and D.O. Renz, Nonprofit Management and Leadership, 9,1 (1998).

[3] Ritchie, W.J. and R.W. Kolodinsky, Nonprofit Management and Leadership, 13, 4 (2003).

[4] Glynn, J.J., et al., Accounting for managers, Melbourne, Australia (2003).

[5] Cameron, K.S., 32, 5 (1986).

[6] Herman, R.D. and D.O. Renz, 18, 4 (2008).

[7] Kirchner, T.A., E.P. Markowski, and J.B. Ford, International Journal of Nonprofit and Voluntary Sector Marketing, 12 (2007).

[8] Hishamudin, M.S., et al., International NGO Journal, 5,5 (2010).

[9] Greenlee, J.S. and D. Bukovinsky, Ohio CPA Journal, 57, 1 (1998).

[10] Herzlinger, R.E. and D.L. Nitterhouse, Cicinnati, Ohio (1995).

[11] Barrett, D. and S.R. Windham, Health Care Management Review, 9, 4 (1984).

[12] Chabotar, K.J., The Journal of Higher Education, 60,2 (1989). 